\title{
The Influence of Welding Process Parameters on aluminium alloy Multi-pass Welding Residual Stress
}

\author{
Cang Song
}

Guidaojiaotong Polytechnic Institute, Shenyang 110023, China

Keywords: multi-pass welding residual stress, SYSWELD, welding speed.

\begin{abstract}
Abstarct.In this paper, we discuss the influence of different preheating temperature and welding speed on welding residual stress through numerical simulation, which takes a certain type of emu car KK middle end of $\mathrm{T}$ type welded joint as an example.Using the double ellipsoid heat source model checking got temperature field that degree of fitting better with experiment, Ensure the accuracy of the welding residual stress in subsequent calculations. We get the fit temperature field we want through the double ellipsoid heat source checked model, this way, the accuracy of the welding residual stress in subsequent calculations is ensured at the same time.
\end{abstract}

\section{Introduction}

At present, the car body of high-speed EMU is widely made of extrusion profiles longitudinal welded light aluminum alloy, whose structure is cylindrical and with the load bearing mode [1]. However, in the process of welding, the welding residual stress is produced due to the difference of weld thermal cycle curve at every point which led by the uneven heating and cooling of the weld.

The research on the rules of the welding stress producing of aluminum alloy car-body not only can tell us the control measures of the of welding stress in welding process, it also can ensure the safety and reliability by the quantitative study of welding stress. There are three aspects that influencing the welding residual stress produced:1.the material 2.the heat source 3.the welding parameter, which plays a more important role such as the welding speed and heat effect[2]. Because of this, we must take effective measures such as improving the welding process and reducing the residual stress of welding components to improve the product welding quality, which has always been what we wanted to pursuit in equipment products manufacturing process [3-4].

\section{The Heat Source Check}

There are five steps to construct a heat source: Establishing a grid, loading the material database, defining the process parameters, check the test results and save the heat source [5].

This paper takes the double ellipsoid heat source model as an example. In the welding process, heat source moves forward along the soldering seam. The energy distribution of anterior and posterior parts is asymmetric due to the influence of welding speed. Always, the front arc energy is greater than the back one [6]. Double ellipsoid heat source model separates the heat source for two $1 / 4$ halves ellipsoids, as shown in figure 1.

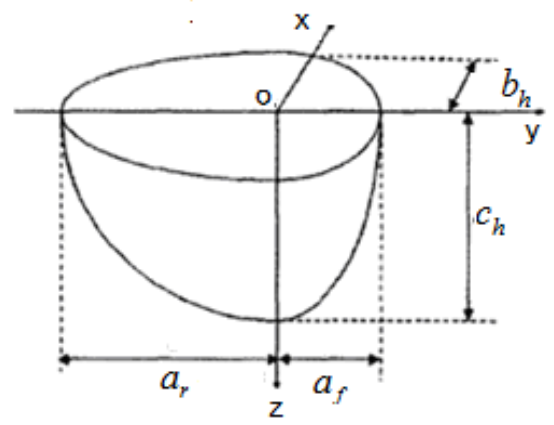

Fig.1 Double ellipsoid heat source model

$a_{f} 、 a_{r} 、 b_{h}$ and ${ }^{c_{h}}$ as heat source parameters, $b_{h}$ affects the weld width, $c_{h}$ affects the 
weld penetration. The determination of these parameters requires a certain experience, which is also very time-consuming. Hypothesis 1 is the ellipsoid heat input, we can draw the ellipsoid heat flux distribution using the double ellipsoid Formula as follows[x]:

The first half of the heat input is:

$$
\begin{aligned}
& q_{f}(x, y, z)=\frac{6 \sqrt{3}\left(f_{f} Q\right)}{a_{f} b_{h} c_{h} \pi \sqrt{\pi}} \exp \left(-\frac{3 x^{2}}{b_{h}^{2}}-\frac{3 y^{2}}{a_{f}^{2}}-\frac{3 z^{2}}{c_{h}^{2}}\right), \mathrm{y} \geq 0 \\
& q_{r}(x, y, z)=\frac{6 \sqrt{3}\left(f_{r} Q\right)}{a_{r} b_{h} c_{h} \pi \sqrt{\pi}} \exp \left(-\frac{3 x^{2}}{b_{h}^{2}}-\frac{3 y^{2}}{a_{r}^{2}}-\frac{3 z^{2}}{c_{h}^{2}}\right), \mathrm{y}<0
\end{aligned}
$$

$$
\begin{aligned}
& 2 \int_{0}^{\infty} \int_{0}^{\infty} \int_{0}^{\infty} q_{f}(x, y, z) d x d y d z \\
& =2 \times \frac{6 \sqrt{3}\left(f_{f} Q\right)}{a_{f} b_{h} c_{h} \pi \sqrt{\pi}} \times \frac{b_{h}}{\sqrt{3}} \frac{\sqrt{\pi}}{2} \times \frac{a_{f}}{\sqrt{3}} \frac{\sqrt{\pi}}{2} \times \frac{c_{h}}{\sqrt{3}} \frac{\sqrt{\pi}}{2}=\frac{1}{2}\left(f_{f} Q\right)
\end{aligned}
$$

A for the second half of the parts is in the same way

$$
\begin{aligned}
& 2 \int_{0}^{\infty} \int_{0}^{\infty} \int_{0}^{\infty} q_{r}(x, y, z) d x d y d z= \frac{1}{2}\left(f_{r} Q\right) \\
& \text { As: } \eta I U_{a}=Q=\frac{1}{2}\left(f_{f} Q\right)+\frac{1}{2}\left(f_{r} Q\right)=\frac{1}{2} Q\left(f_{f}+f_{r}\right) \\
& \text { So: } f_{f}+f_{r}=2, f_{f}=\frac{2 a_{f}}{a_{r}+a_{f}}, f_{r}=\frac{2 a_{r}}{a_{r}+a_{f}}
\end{aligned}
$$

The first line of welding heat source model :V=17.6mm/s,I=210A, $U=23.6 \mathrm{~V}, \mathrm{E}=0.7, \mathrm{Q}=3469.2 \mathrm{~J}$; The second line of welding heat source model :V=8.8mm/s,I=200A, $U=23.5 \mathrm{~V}, \mathrm{E}=0.7, \mathrm{Q}=3290 \mathrm{~J}$; The given temperature field coming from the checked double ellipsoid heat source model is shown in figure 2.

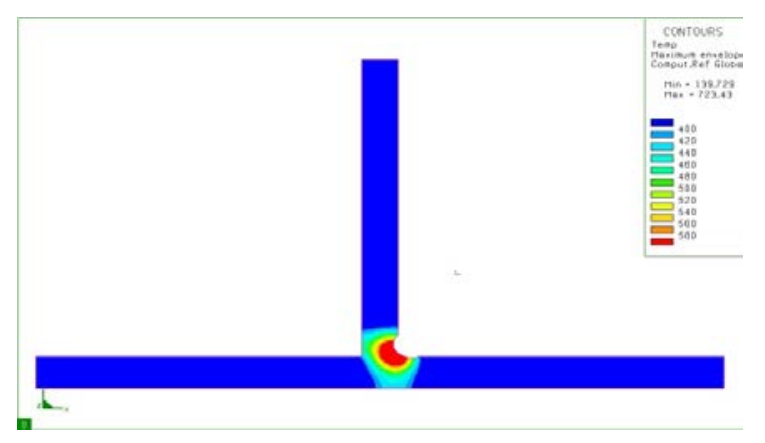

Fig.2 The temperature field cloud picture

\section{The Results and Analysis of Welding Residual Stress}

Weld metal contains two metal parts, they are the fusion zone and heat affected zone. The highest temperature can reach the boiling point of weld area, while, it will drop to room temperature extremely away from the heat source.

The formation of weld metal needs rapid cooling and solidification of liquid metal in the molten pool. Welding thermal stress is produced by the uneven heat input, so the correct welding temperature field is the precondition that we get the residual stress in simulation welding process.

In order to observe the distribution of residual stress, we selected two critical path, line1 and line2. Line1 is a straight line on the surface of weld center; line2 is perpendicular to the weld and a line through the center of weld. 


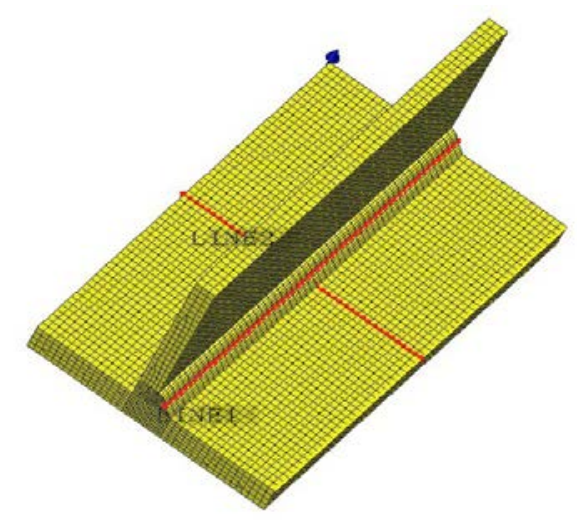

Fig.3 Selecting two critical path line1 and line2

In order to study the effect of welding speed and preheating temperature for welding simulation, the study of the welding speed and temperature of the $\mathrm{T}$ joint consists of the following solutions:

(1) The influence to residual stress by changing welding speed

On the condition of the given preheating temperature(100 degrees Celsius), we change the welding speed: the first welding speed is V1(The first line of welding speed is $15.84 \mathrm{~mm} / \mathrm{s}$, the second one is $7.92 \mathrm{~mm} / \mathrm{s}$ ), the second welding speed is V2(The first line of welding speed is $17.6 \mathrm{~mm} / \mathrm{s}$, the second one is $8.8^{\mathrm{mm} / \mathrm{s}}$ ), The third welding speed is V3(The first line of welding speed is $19.36 \mathrm{~mm} / \mathrm{s}$, the second one is $9.68 \mathrm{~mm} / \mathrm{s}$ ).

Analyze Line1 (perpendicular to welding line) and Line2 (along the path) from landscape orientation and portrait. We got what as shown in figure 4.

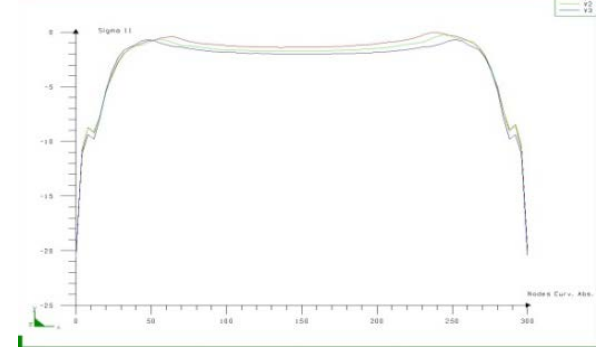

(a) The distribution of transverse residual stress on line 1

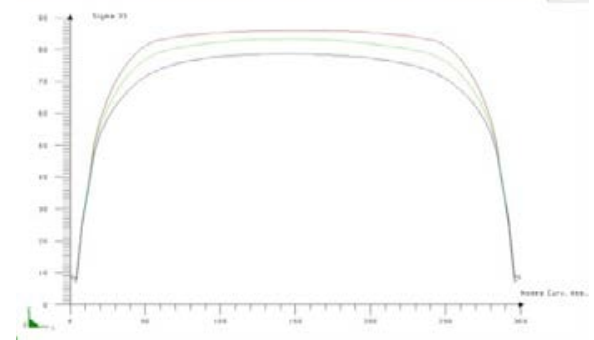

(b) The distribution of longitudinal residual stress on line 1

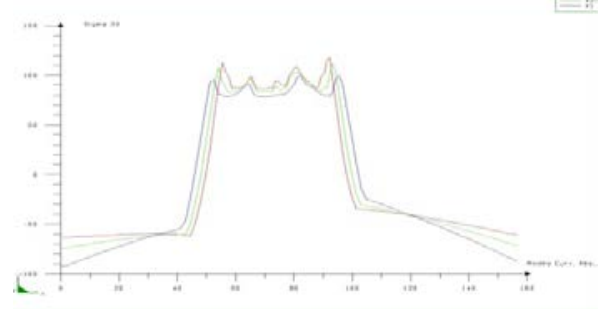

(c) The distribution of transverse residual stress on line 2 


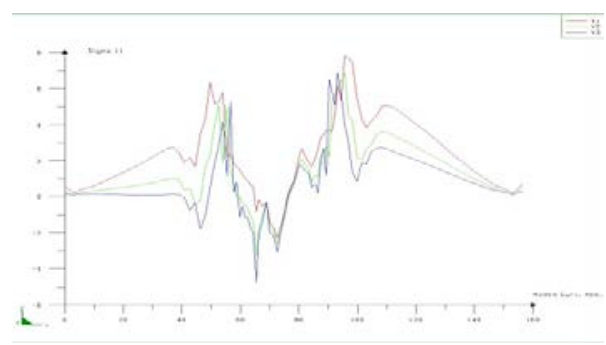

(d) The distribution of longitudinal residual stress on line 1

Fig.4 The influence of welding speed to residual stress

As shown in figure 4 (a), when Line1 along the weld direction of the transverse, welding residual stress is the smallest at the first welding speed V1, followed by V2.V3 is the maximum one. When Line1 along the weld longitudinal direction, as shown in figure 4 (b), we get the opposite result. The test result of Line2 is the same as Line1, as shown in figure 4 (c) and 3 (d).

(2) The influence of changing preheating temperature on the residual stress

In order to study the effects of preheating temperature on the welding residual stress, under the condition of the determined welding speed, we change the preheating temperature: T1 ( 20 degrees Celsius), T2 (100 degrees Celsius) and T3 (180 degrees Celsius) respectively.

The calculation results of the model as shown in figure 5 through reloading and repeated calculation. When it is along the weld direction of the transverse, welding residual stress is the biggest at the preheating temperature T1, followed by T2.T3 is the minimum one. When it is along the weld longitudinal direction, we get the same result.

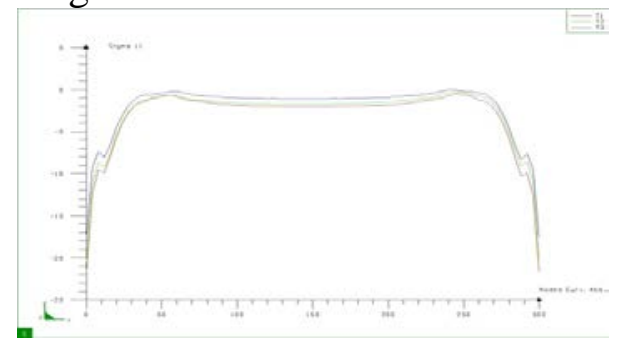

(a) The distribution of transverse residual stress on line 1

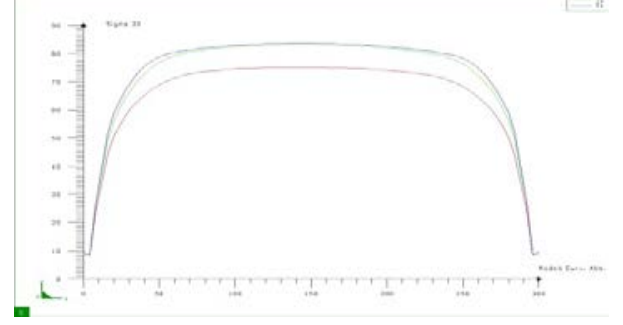

(b) The distribution of longitudinal residual stress on line 1

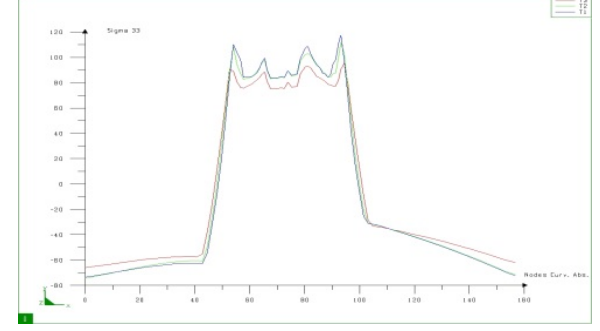

(c) The distribution of transverse residual stress on line 2 


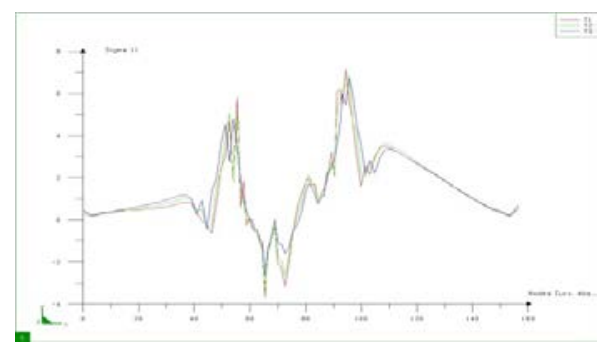

(d) The distribution of longitudinal residual stress on line 2

Fig.5 The influence of changing preheating temperature on the residual stress

Finally, based on the above result of analysis, preheating can reduce the welding residual stress effectively. It is because the rapid heating is local during the welding process. Temperature gradient of the weld area is higher. If adopting the way of preheating before welding can reduce the heat shock and the temperature gradient welds, the welding residual stress reduces at the same time. Nevertheless, it doesn't mean that the preheating temperature is higher, the better for its structure. Existing research shows that the aluminum alloy material will be affected adversely in performance and heat treatment under high temperature. At the same time its ability of resistance to corrosion, cracking and tensile strength also reduces.

\section{Conclusion}

Basing on SYSWELD software, one can draw a conclusion through welding numerical simulation of the T-joint multi-channel welding at different speeds and in different preheating temperatures:

Comparing three velocity values of the multi-pass welding, T-joint welding residual stress is calculated. The results show that reducing the welding speed within a certain scope can reduce the weld residual stress at a given temperature.

One can reach the result that comparing three schemes of multi-pass welding under different preheating temperature conditions, the value of welding residual stress will change once the welding preheating temperature changes within a certain range. The temperature is higher, the welding residual stress can be reduced significantly, but it is not the higher, the better.

\section{Acknowledgements}

The research work was supported by China Railway Corporation R\&D program (2013J012-B); National Natural Science Foundation (51220001, 51405057); Education Office of Liaoning province Scientific Research Program (L2014182).

\section{References}

[1] LIU Zhi-ping, WANG Jin-jin, WANG Li-fu,et al.Welding Technology of Aluminum Alloy CRH3 High Speed EMU[J].Hot Technology,2010,25(16):10-14.

[2]GOU Gou-qing,YU Jin-peng,ZHANG Li-min.Research of Welding residual Stress about Aluminum Alloy[J].Electric Welding Machine,2011,44(11):10-14.

[3]ZHAO Dong-sheng, LIU Yu-jun.Welding Residual Stress Calculation of Carbon Streel and Stain-less Steel Joint [J].Welding Journal, 2012, 33(1):93-95.

[4]WANG Neng-qing, TONG Yang-gang, Effects of Welding Heat Source Parameters on Residual Stress and Distortion in Thin Plate Joint[J].Welding Journal,2012,33(12):97-100.

[5]HU Sha-sha.NumericalSimulation on Flat Welding Temperature Field for Submerged Arc Welding [J].Hot Working Technology,2013,42(3):210-212. 
[6]ZHOU Jian-xin,XU Hong.Effect of Specimen Dimension on Welding Residual Stresses[J].Welding Journal,2006,3(3):96-100. 